LA-UA $-86-2273$

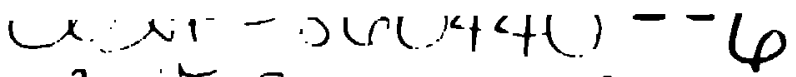

$$
\begin{aligned}
& \text { CONF-8404.25 - } 34
\end{aligned}
$$

TirLE. Multifragmentation in Intermediate Energy Heavy Ion Collisions

AUTHOR(S) B.V. Jacak, H.C. Britt, A.I. Gavron, J. Wilhelmy, Los Alamos National Laboratory

K.G.R. Doss, G. Claesson, H.-A.Gustafsson, J.W. Harr1s, A.M. Poskanzer, H.-G. Ritter, L. Teltelbaum, M. Tincknell, S. We1ss, H. Wieman, LBL, Berkeley, CA

K.-H. Kampert, B. Kolb. H.R. Schmidt, Gesellschaft fur Schwerloneforschung, West Germany

R. Ferguson, ORNL, Oak RIdge, TN

Euamited ro: Second International Workshop on Local Equilibrium in Strong Interaction Physics, Santa Fe, MI, Apr11 9-12, 1986; and National Meeting of the American Chemical Soclety, New York, NY, Apr11 14-18, 1986

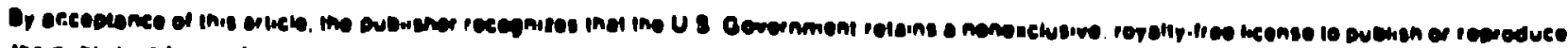

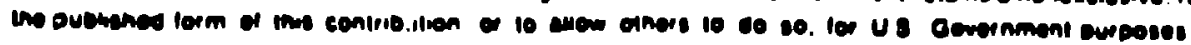


MULTIFRAGMENTATION IN INTERMEDIATE ENERGY HEAVY ION COLLISIONS

B. V. Jacak, ${ }^{\star}$ H. C. Britt, ${ }^{\star}$ G. Claesson, ${ }^{\star \star}$ K. G. R Doss, $^{\star \star}$ R. Fefguson, ${ }^{\ddagger \neq}$ A. I. Gavron, H.-A. Gustafsson, ${ }^{*}$ H. Gutbrod, J. W. Harris,

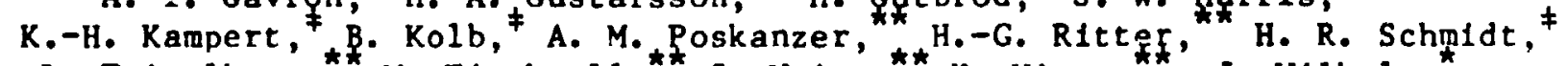
L. Teltelbaum, ${ }^{\star}$ M. IIncknel1, ${ }^{\star}$ S. Welss, ${ }^{\star}$ H. Wleman ${ }^{\star}, J$. W1lhelmy

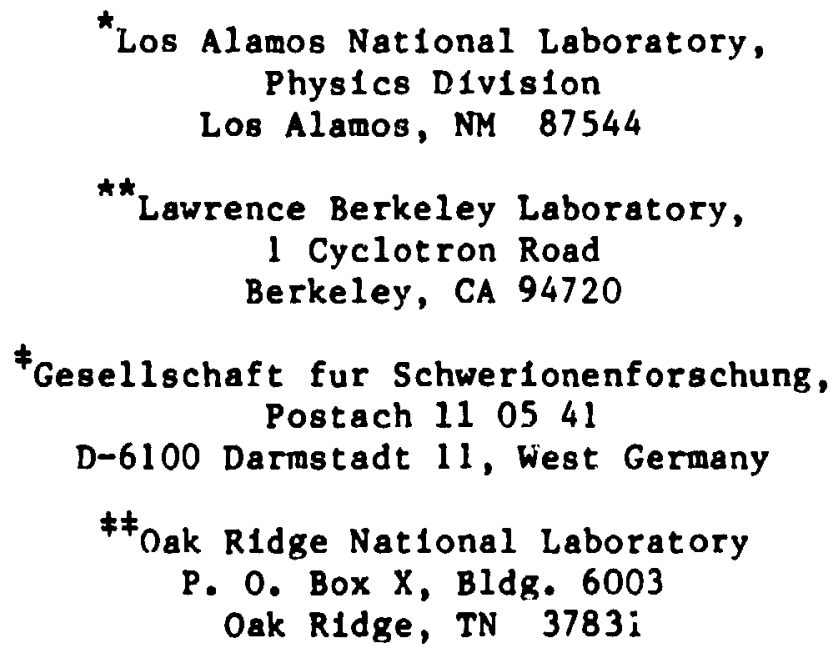

There has been considerable recent interest in the production of Intermediate mass flagments ( $>4$ ) in intermediate and high energy nucleus-nucleus collistons. The mechanism for production of these fragments 18 not well inderstood and has been described by models employing a variezy of assumptions. Some examples are: disassembly of a system in thermal equilibrium into nucleons and nuclear fragments, 1,2] 11qu1d-vapor phase transitions in nuclear malter, 3 ] $f$ ina] state coalescence of nucleons ${ }^{4}$ and dynamical correlations between nucleons at breakup 5,6 ].

Previous studies of fragment production, with one exception, 7 ] have been single particle inclusive meagurements: the observed fragment mass (or charge) distributions can be described by all of the models above. io gain insight into the fragment production mechanism, we used 
the GSI/LBL Plast1c Ball/Wall detector system ${ }^{8}$ to get full azimuthal coverage for intermediate mass fragments $(2<10)$ in the forward hemisphere in the center of mass system while measuring all the light particles in each event.

The complete measurement of 1 ight particles ( $p, d, t,{ }^{3} \mathrm{He},{ }^{4} \mathrm{He}$ ) allows us tu determine the charge multiplicity of participant baryons, which Increases as the impact parameter between the profectile and target nuclel gets omaller. In addition, the complete measurenent of light particles allows us to perform global analyses of the events and look for collective effects in fragment emisolion by comparing to flow effects oeen in the 11ght particles. Lastly, the large acceptance for intermediate mass fragments in the Plastlc Ball allows us to neasure their multiplicities event-by-event. This experiment should help to difforentiate the varlous models by allowing a better characterization of the system breaking up, as well as ylelding information on the 1mpact parameter of the collision. We weasured fragmentation for 200 MeV/nuclen Au + Au and $\mathrm{Au}+\mathrm{Fe}$, using the Inverae kinematics in the latter case to focus fragments from the large reaction partner into our detectors. Presented here are first results from the experiment. These will not yet allow us to deturmine the exact fragmentation mechanisu, but will provide many constralnts on the results of the various models.

The observed particlpant charge multiplicity distribution for Au + Au 1 s sown in figure 1 . We have used thls quantity to oort the events Into groups according to Impact parameter, as Indicated by the 1 ines in the flgure. The events with the fewest observed charges (labeled "mull") correspond to the most peripheral coll1sions, while the events with the highest charge multiplictties ("mul5") arine from centra) coll1sions. The drop in the number of events with very low 


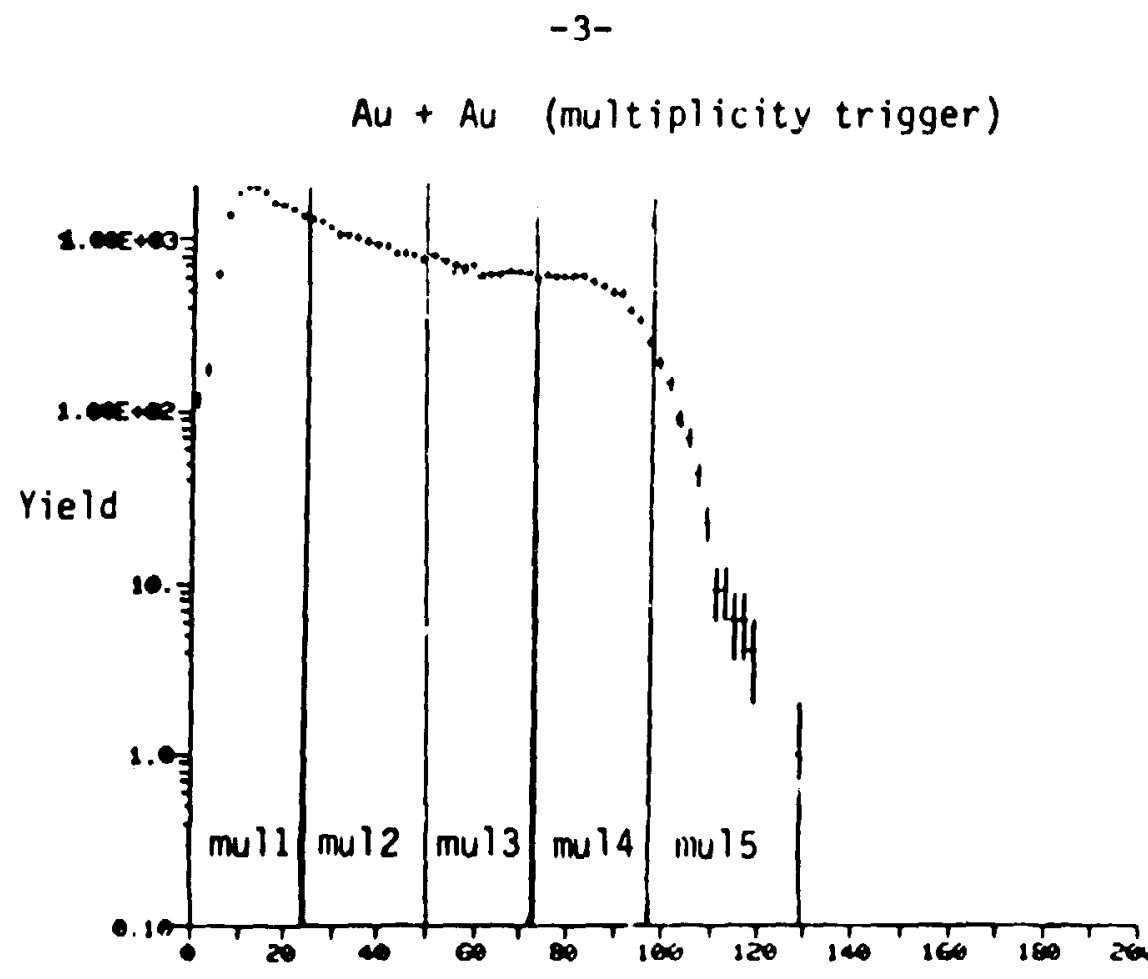

Participant Charge Multiplicity

F1g. 1. Participant charge multiplicity distribution for $\mathrm{Au}+\mathrm{Au}$.

multiplicities is a result of the trigger used in t.ee experiment, which was designed to discriminate against the most peripheral collisions.

Figure 2 shows a density plot of the 1nvariant cross section for l1thlum fragments from $\mathrm{Au}+\mathrm{Au}$, as a function of the rapldity and the perpendicular momentum per nucleon. The five parts of the flgure correspond to the five cuts on the particlpant charge aultipliclty indicated in figure 1. No corrections for the angular and energy cutoffs in the detector have been applied to the data. Thus two distinct sections are visible in each plot, corresponding to the two subsections of the detector system which were sensitive to intermedlate mass frapments. 


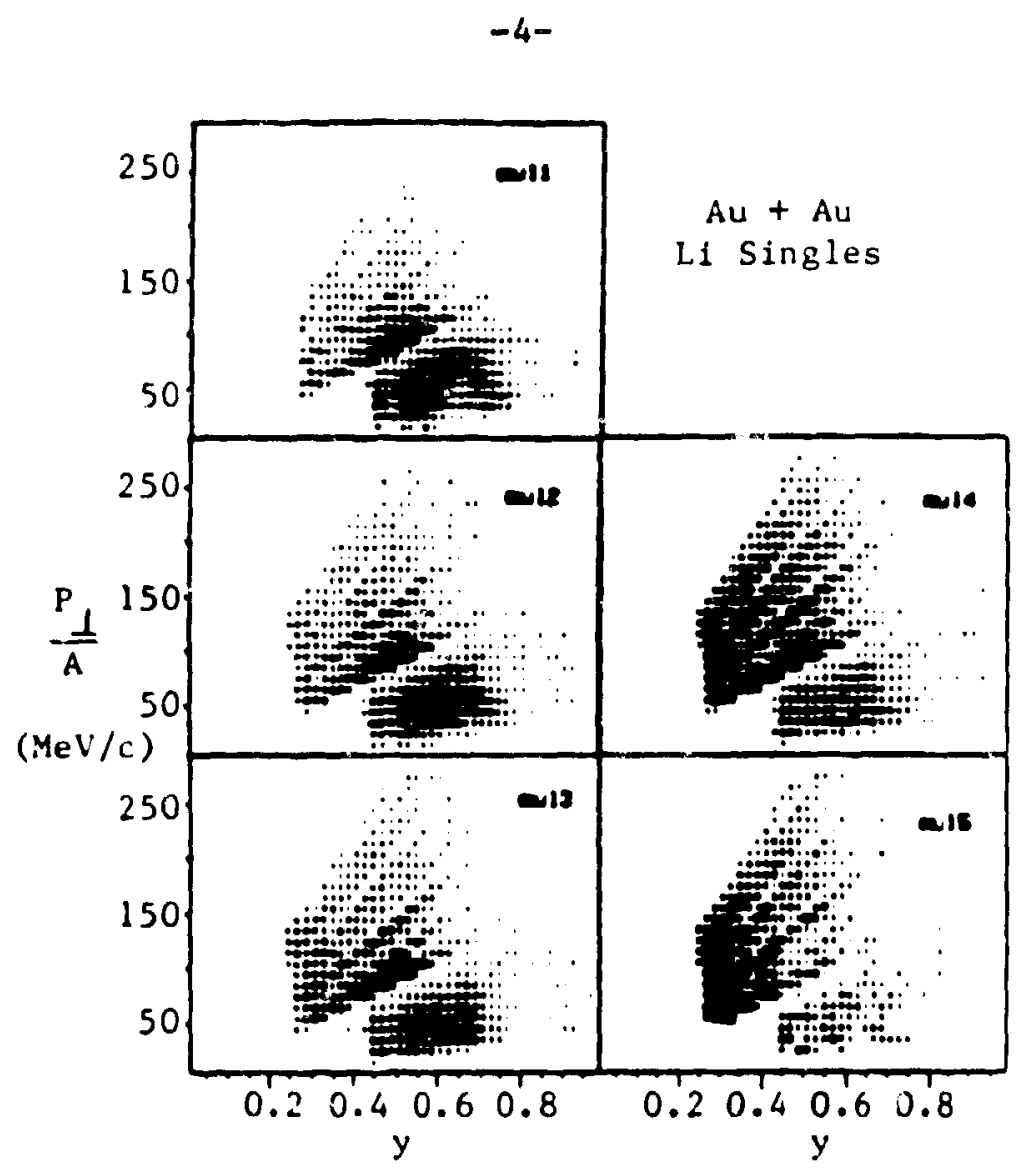

F1g. 2. Multiplicity selected rapid1ty plots for 11thlum fragments for $\mathrm{Au}+\mathrm{Au}$.

It is evident from the figure that peripheral collisions give rise to fragments with rapldities very close to the beam rapldity, consistent with expectations for fragmentation of a sightly exclted projectile. In the "mull" plot we see a hole in the yield at exactly the beam rapidity, corresponding to coulomb repulsion between the emitted lithlum fragment and heavy remnant of the Au profectile. In events where a profectlle remnant is observed, the azimuthal angles of the remnant and fragments are correlated, supporting the plcture of fragments evaporated Erom a large profectlle residuc. 
In the more central collisions in the highest multipliclty bins, we see many lithlum fragments emitted with imaller rapiditles, Intermediate between those of the target and the profectile. In contrast to the forward peaked angular distributions arising from peripheral solligions, these fragments are emitted relatively 1sotropically in the center of mass system. Such behavior 1s what one wight expect when the profectile nucleons impart more energy to the target and create an exclted region which moves at a velocity approximately halfway between that of the profectile and the target.

The transttion between the peripheral and central collisions is very smooth, with a gradual shift in the rapidities of the observed fragments away from the profectile rapldity. In order to check if both projectile-like and midrapidity fragments are formed in the same event, we chose events with mulciple fragments and required that at least one fragment fall into a midrapldity window. We made a rapidity plot anilar to figure 2 of the other fragments in the ovent, and found that the mixing cccurs event-by-cvent; even in the central colliolons where midrapldity fragments are formed, we observe come assoclated profectlle rapldity fragments.

In order to check our detection efficlency for multiple fragments, we summed the charges observed in the forward c.m. hamisphere for the Au + Au reaction and compared this with the charge of one Au nucleus. The result is shown in figure 3, plotted as a function of the particlpant charge multiplicity. For peripheral collisions, we observe a large profectlle remnant in many evente, thesc correspond to tha amall lobe on the left (low multipliclty) side of the flgure. As the charge of the profectlle remnant is not well measured, it 18 assigned one half the charge of the profectlle. It 1 a clear that the remnant charge 1s undereatimated for the most peripheral collisions and overestimated as the impact parameter and profectile remant become 
$A u+A u$

\section{$\Sigma \mathbf{Z}$}

for particles with

$$
{ }^{\theta} c_{. m}<90^{\circ}
$$

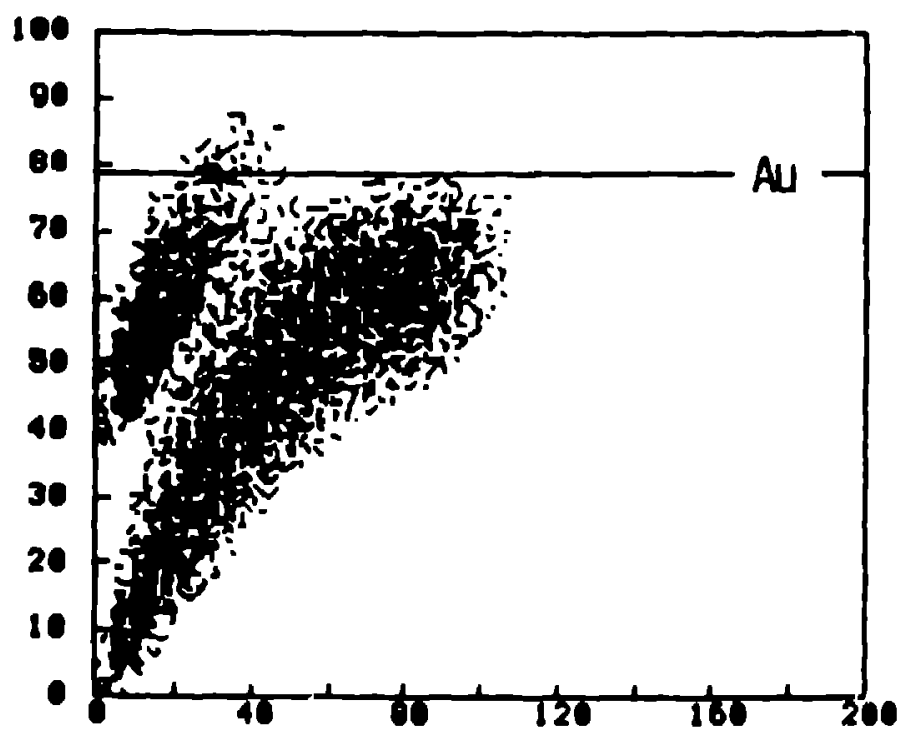

\section{Porticlpant Chorge Multiplicity}

F1g. 3 Sum of charges observed in forward c.m. hemisphere, as a function of the participant charge mitiplictty.

analler. For central collision (large multiplicltieg), we observe almost all of the Au charge in the form of 11ght and Intermediate mass fragments. These regults indicate that in central collisions the system breaks up 1nto rather small pleces with no large remant. Also, we gain confidence that we may study fragment multipifities event by event due to the high efficlency of the detector oyster.

The total Intermediate mass fragment multiplicity 18 found to Increase with increasing participant baryon charge multiplicity. In peripheral colliglons, the few fragments which are formet are preferentially emitted at angles less than ten degrees in the lab. More fragments are produced in central collisions, and these fragments are iound at larger angles. 
Figure 4 shows the multiplicity distributions for fragments observed at angles between 10 and 30 degrees in the lab. It should be noted that for the Au + Au system, 30 degrees in the lab corresponds to 90 degrees in the center of mass frame. The five curves correspond to the same five cuts on the participant charge multiplicity that were described in figure 1 and used in figure 2. In central collisions, the most probable fragment multiplicity is $3-4$, with a tall out to as many $a 9$ fragments. For peripheral collisions the distribution peaks at zero to one fragment, with a smaller tall to high multiplicities. The mulriplicities of fragments emitted to omall angles are very low, regardless of 1mpact parameter.

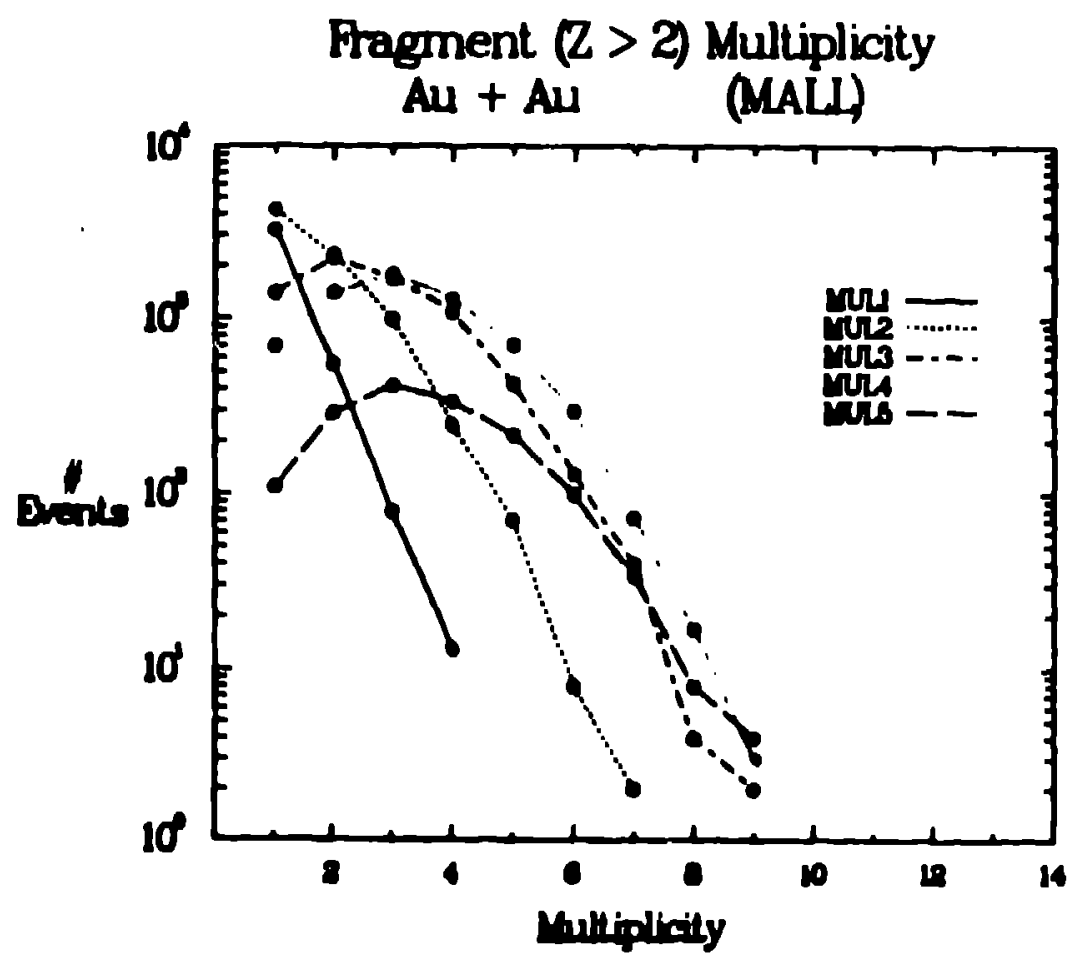

F1g. 4. Multiplicity distributions of intermediate mass fragment detected at 10-30 degrees in the laboratory. 
Collective flow of nuclear matter upon re-expansion has been proposed as an important signature of compression effects. Two collective effects, the side-splash of the participants and the bounce-off of the spectator nucleons have been observed at the Plastic Bal19]. A sensitive test for collective flow can be found in the transverse momentum analysis of Danielewicz and Odyniecl0]. This method determines the reaction plane from the transverse momentum transfer between the forward and backward hemlspheres in the center of mass, and then examines the mean transverse momentum per nucleon $\langle p x / A\rangle$ in this reaction plane as a function of the center of mass rapidity. By removing auto-correlations (1.e. calculating the reaction plane for each ind vidual particle from the transverse momentum bum of all the other particles), this method is sensitive to the real dynamic correlations.

Figure 5 shows the mean transverse momentum per nucleon projected

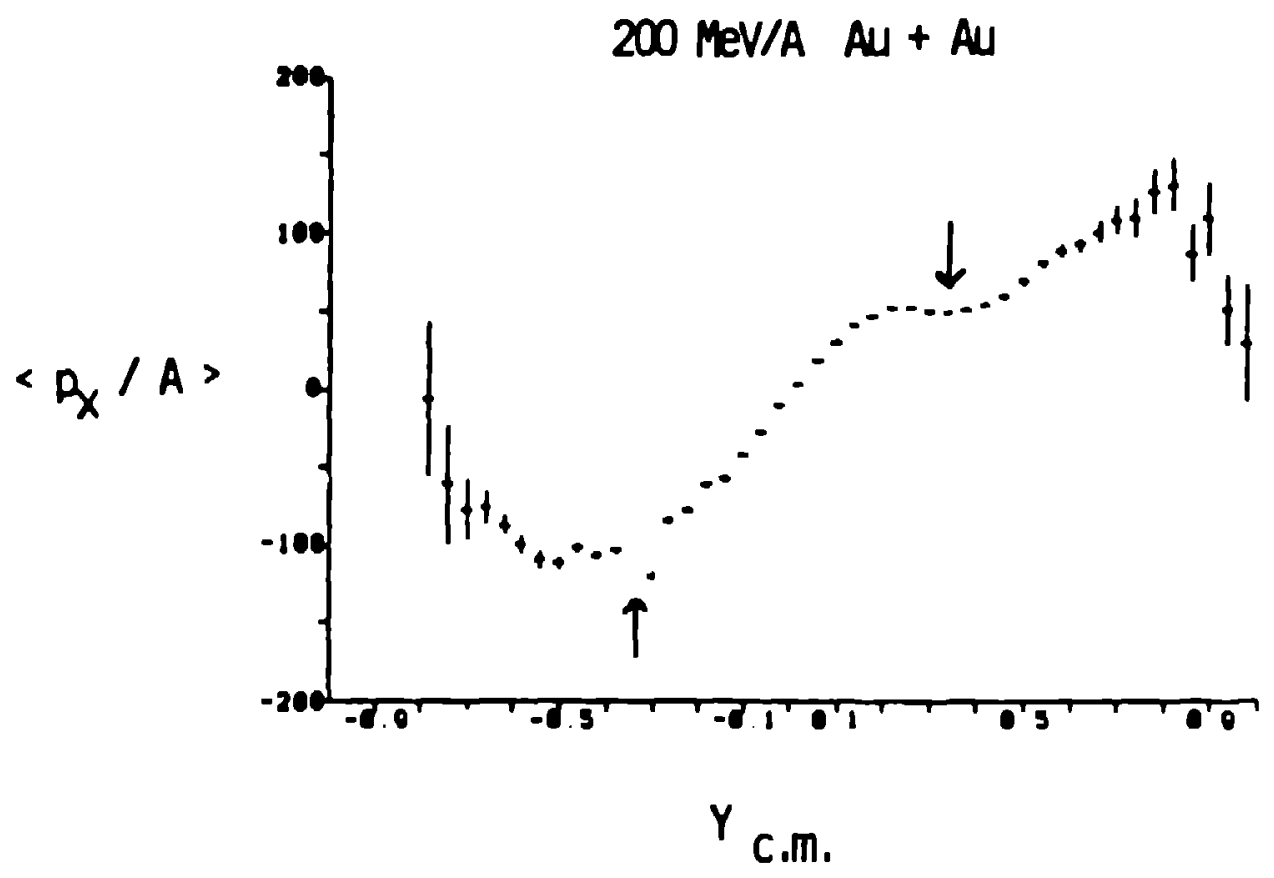

F1g. 5. Mean transuerge momentum per nucleon in the reaction plane, as a function of c.m. rapidity for $A u+A u$. 
Into the flow plane for the Au + Au reaction. The calculation includes only $2-1$ and $2-2$ particles, and may be compared to analyses of earller Plastic Ball experiments ${ }^{11}$. All observed 11ght particles are included In the figure; those originating from the projectile or target spectators were not removed. The curve shows the s-shape typical for the collective transverse momentum transfer between the forward and backward hemispheres. Close. to the target and projectile rapidities the curve bends towards the axis because of contamination from opectator matter.

We have examined the intermediate mass fragments for flow effects by looking at the azimuthal correlation between the reaction plane and the emission angle of the fragments. We find that fragments are preferentially emitted in the same direction as the flow direction, and that th1s correlation gets stronger for more massive fragments.

As a first otep in studying the origins of wultiple fragments, we construct the "effective source" of the fragments by summing the 4-momenta of the observed fragments. This source moves with a velocity oimllar to the beam velocity in the case of peripheral collistons, and s lows down as the fmpact parameter decreases. We again calculated the reaction plane from the light particles, and looked at the projection of the "effective source" transverse momentum per nucleon in and out of the reaction plane. As with the fragment singles, the source azimuthal angle is correlated with the reaction plane. The transverse momentum per nucleon in the reaction plane increases for more central coll1olons, reaching a maximum of about $150 \mathrm{MeV} / \mathrm{c}$. Perpendicular to the reaction plane, the source transverse momentum shows no preferred direction. 
We are currently studying whether the intermediate mass fragment energy distributions and multiplicities can be reproduced with models Incorporating the varlous assumptions mentioned earlier. These models must also reproduce the observed flow effects, thus rather stringent criteria have already been established by these experiments.

\section{REFERENCES}

1. J. Randrup and S. E. Koonin, Nucl. Phys. A356, 223 (1981). G. Fal and J. Randrup, Nucl. Phys. A404, 551 (1983).

2. J. P. Bondorf, R. Donangelo, I. N. Mlshustin, C. J. Pethick and K. Sneppen, Phys. Lett, 150B, 57 (1985).

3. G. Bertsch and P. J. Siemens, Phys. Lett. 126B, 9 (1983).

4. H. H. Gutbrod, A. Sandoval, P. Johansen, A. M. Poskanzer, J. Gosset, W. G. Meyer, G. D. Westfall, and R. Stock, Phys. Rev. Lett. $37,667(1976)$.

5. B. Strack and J. Kno11, Z. Phys. A315, 249 (1984).

6. G. E. Beauvals, and D. H. Boal, Univ. of I1l. preprint P/86/2/26, 1986.

7. A. I. Warwlck, H. Wieman, H. H. Gutbrod, M. R. Maler, J. Peter, H. G. Rttter, H. Stelzer, F. Welk, M. Freedman, D. J. Henderson, S. B. Kaufman, E. P. Steinberg, and B. D. Wilkins, Phys. Rev. C27, 1083 (1983).

B. A. Baden, H. H. Gutbrod, H. Lohner, M. R. Maler, A. M. Poskanzer, T. Renner, H. Rledesel, H. G. Ritter, A. Warwick, F. Welk, and H. Wleman, Nuc1. Inst. Meth. 203, 189 (1982).

9. H. A. Gustafsson, H. H. Gutbrod, B. Kolb, H. Lohner, B. Ludew1gt, A. M. Poskanzer, T. Renner, H. Riedesel, H. G. Ritter, A. Warwick, F. Welk, and H. Wleman, Phys. Rev. Lett. 52, 1590 (1984).

10. P. Dantelew1cz and G. Odyniec, Phys. Lett. 157B, 146 (1985).

11. H. A. Gustafsson, H. H. Guttw1, B. Kolb, H. Lohner, B. Ludewigt, A. M. Poskanzer, T. Renner, H. Riedesel, H. G. Ritter, T. Semlarczuk, J. Stepantak, A. Warwlck and H. Wleman, Z. Phys. A321, 389 (1985).

\section{DISCLAIMER}

This report was prepared as an account of work sponsored by an agency of the United States (iovernment. Neither the United States Goverument nor any agency thereof, nor any of their employees, makes any warranty, express or implied, or assumes any legal liability or responsibility for the accuracy, completencss, or usefulness of any information, apparatus, product, or process disclosed, or represents that its use would not infringe privately owned rights. Reference herein (o) any specific commercial product, process, or service by trade name, trademark. manufacturer, or otherwise does not necessarily constitute or imply its endorsement, recom!mendution, or fuvoring by the United St:tes Government of any agency thereof. The views and opinions of authors expressed herein do not necessarily state or reflect those of the United States Government of any agency thereof. 